\begin{tabular}{|c|c|c|}
\hline Beitr. Ent. & Keltern & ISSN 0005-805X \\
\hline $56(2006) 1$ & S. $141-154$ & 15.08 .2006 \\
\hline
\end{tabular}

\title{
New species and records of Masuria CAMERoN, with a key to species
}

\author{
(Coleoptera: Staphylinidae, Aleocharinae)
}

With 38 figures

VOLKer Assing

\section{Summary}

Four species of Masuria CAMEron are described and illustrated: M. (Masuria) kleebergi sp. n. (Nepal: Rolwaling Himal), M. (M.) follite sp. n. (Nepal: Rolwaling Himal), M. (M.) sculpticollis sp. n. (Nepal: Rolwaling Himal), and $M$. (Oncosomechusa) brevipennis sp. n. (China: N-Yunnan). Additional records of four previously described species are reported from Nepal and China. A key to species is provided. The genus now includes 24 species and has become known only from the Himalaya and China.

\section{Zusammenfassung}

Vier Arten der Gattung Masuria Cameron werden beschrieben und abgebildet: M. (Masuria) kleebergi sp. n. (Nepal: Rolwaling Himal), M. (M.) follita sp. n. (Nepal: Rolwaling Himal), M. (M.) sculpticollis sp. n. (Nepal: Rolwaling Himal) und $M$. (Oncosomechusa) brevipennis sp. n. (China: N-Yunnan). Für vier weitere Arten werden neue Nachweise aus Nepal und China gemeldet. Eine Bestimmungstabelle wird erstellt. Die Gattung umfasst nunmehr 24 Arten; ihre Verbreitung ist auf den Himalaja und China beschränkt.

\section{Keywords}

Coleoptera - Staphylinidae - Aleocharinae - Masuria - Palaearctic region - Nepal - Himalaya - China - new species - new records

\section{Introduction}

The genus Masuria Cameron, 1928 previously comprised 20 species, 15 in the nominal subgenus and five in the subgenus Oncosomechusa PACE, 1982. The vast majority of species (17) have become known from the Himalaya; only three species have been reported from China (Yunnan, Gansu) (Assing 1998, 2004; PACE 1989, 1997).

An examination of recently collected material made available to me since the latest contribution to the genus (AssING 2004) yielded not only various additional records of described species, but also five new species, most of them from the Rolwaling Himal in eastern Nepal. Three of them are represented only by females. Nevertheless, two of these species are described below, since they are separated from all their congeners by highly 
distinctive external characters. The fifth undescribed species is represented by one female from the Manaslu region, Nepal. As the external and the sexual characters are not very distinctive, however, a description is here refrained from.

\section{Material, measurements, and abbreviations}

The material treated in this study is deposited in the following collections:

cAss author's private collection

cKle private collection $A$. Kleeberg, Berlin

cSch private collection M. Schülke Berlin

Total length was measured from anterior margin of labrum to abdominal apex (with abdomen extended), elytral length from apex of scutellum to elytral hind margin.

\section{Species descriptions and additional records Masuria (Masuria) picipes CAMERoN}

Additional material examined: Nepal: 17 exs., Dhaulagiri, Baglung Lekh, Tara Khola, 2000 m, 18.V.2004, leg. Kleeberg (cKlee, cAss); 1 ex., Dhaulagiri, Baglung Lekh, upper Tara Khola, 2600 m, 18.V.2004, leg. Kleeberg (cKle); 3 exs., Dhaulagiri, Baglung Lekh, upper Okhle village, 2460 m, 13.V.2004, leg. Kleeberg (cKle, cAss); 1 ex., Dhaulagiri, Baglung Lekh, ca. $30 \mathrm{~km}$ W Baglung, northern Tara Khola, 2700-2900 m, 18. V.2004, leg. Kleeberg (cKle).

Masuria picipes is one of the more widespread species of the genus and has been reported from several localities in Nepal and northern India.

\section{Masuria (Masuria) loebli PACE}

Additional material examined: Nepal: 2 exs., Rolwaling Himal, between Simigaon and Nyimare, bank of Rolwaling river, $2700 \mathrm{~m}, 17 . \mathrm{V} .2000$, leg. Kleeberg (cKle, cAss); 1 ex., Rolwaling Himal, between Simigaon and Nyimare, Rolwaling river valley, $2600 \mathrm{~m}, 17 . \mathrm{V} .2000$, leg. Kleeberg (cKle); 1 ex., Rolwaling Himal, W Daldung La pass, $3300 \mathrm{~m}, 30 . \mathrm{V} .2000$, leg. Kleeberg (cKle).

The species had previously been reported from Bagmati, Nuwakot, and Khandbari Districts in Nepal (Assing 1998, 2004, PACE 1989).

\section{Masuria (Masuria) annapurnae AssING}

Additional material examined: Nepal: 4 exs., Dhaulagiri, Baglung Lekh, ca. $30 \mathrm{~km}$ W Baglung, northern Tara Khola, $2800 \mathrm{~m}, 20$. V.2004, leg. Kleeberg (cKlee, cAss); 1 ex., same data, but N Tara Khola, 2500$2700 \mathrm{~m}, 18$.V.2004, leg. Schmidt (cKle); 4 exs., Dhaulagiri, Baglung Lekh, upper Okhle village, $2460 \mathrm{~m}$, 13.V.2004, leg. Kleeberg (cKle, cAss); 2 exs., Dhaulagiri, Baglung Lekh, upper Tara Khola, $2600 \mathrm{~m}$, 18.V.2004, leg. Kleeberg (cKle, cAss); 1 ex., Dhaulagiri, Baglung Lekh, ca. $30 \mathrm{~km} \mathrm{~W} \mathrm{Baglung,} \mathrm{northern} \mathrm{Tara}$ Khola, $2800 \mathrm{~m}, 20$. V.2004, leg. Kleeberg (cKle); 1 ex., Dhaulagiri, Baglung Lekh, ca. $25 \mathrm{~km}$ W Baglung, 2700-2900 m, 15.V.2004, leg. Kleeberg (cKle).

This recently described species was previously known only from the Annapurna region and is here reported from the Dhaulagiri range for the first time. 
Masuria (Masuria) kleebergi sp. n. (Figs. 1-14)

\section{Type material:}

Holotype ơ: Ost-Nepal, Rolwaling Himal / Rolwaling Tal, zw. Simigaon u. Nyimare, $2600 \mathrm{~m}, 17.05 .2000$, leg. A. Kleeberg / Holotypus ơ Masuria kleebergi sp. n. det. V. Assing 2006 (cAss). Paratypes: 7 exs.: same data as holotype (cKle, cAss); 2 exs.: same data, but $2700 \mathrm{~m}$ (cKle, cAss); 8 exs.: Nepal, Rolwaling vall., Dugong Kharka, 2700$2600 \mathrm{~m}, 17.05 .2000$, leg. J. Schmidt (cKle, cAss); 3 exs.: Ost-Nepal, Rolwaling Himal / Rolwaling Tal, Nyimare, 3300 m, 19.05.2000, leg. A. Kleeberg (cKle); 2 exs.: Ost-Nepal, Rolwaling Himal / Rolwaling Tal, Umg. Nyimare, 3300 m, Spritzmoos, 18.05.2000, leg. A. Kleeberg (cKle).

\section{Description:}

Species of intermediate size, $3.4-4.3 \mathrm{~mm}$. Habitus as in Fig. 1. Blackish brown to black; legs brown to blackish brown, with the tarsi reddish brown and sometimes the bases of the meso- and metafemora paler; antennae dark brown to blackish brown, with the basal 1-3 antennomeres reddish brown.

Head with very dense, moderately coarse, and well-defined puncturation, interstices mostly reduced to narrow ridges and without microsculpture; eyes bulging, distinctly projecting from lateral outline of head (Fig. 2). Antennae rather slender (Fig. 3); preapical antennomeres only weakly transverse.

Pronotum relatively slender, $1.20-1.25$ times as wide as head and approximately 1.15 times as wide as long; lateral margins weakly angled anterior to middle, shallowly concave between lateral and posterior angles; posterior angles well-marked; near posterior angles usually with distinct oblong impression; puncturation similar to that of head, predominantly well-defined; interstices without microsculpture (Fig. 2).

Elytra 1.25-1.30 times as wide and approximately 0.95 times as long as pronotum; puncturation similar to that of pronotum, but slightly sparser and sometimes slightly coarser; interstices on average narrower than diameter of punctures (Fig. 2). Hind wings fully developed. Metatarsus long and slender, metatarsomere I approximately as long as the combined length of II and III.

Abdomen approximately $0.80-0.85$ times as wide as elytra, widest at base (segments III/ IV), gradually tapering towards apex; puncturation very dense and somewhat granulose in anterior impressions of tergites III-V, fine and very dense on posterior half of tergite III, and moderately dense on remainder of abdominal surface, distinctly sparser on posterior than on anterior tergites; pubescence greyish and decumbent; surface without distinct microsculpture; posterior margin of tergite VII with pronounced palisade fringe (Fig. 4).

$0^{*}$ : tergite VIII transverse and with convex posterior margin (Fig. 5); sternite VIII weakly oblong and with broadly convex posterior margin; median lobe of aedeagus large, ventral surface of ventral process distinctly excavate (Figs. 7-11).

o : tergite VIII transverse, its posterior margin obtusely angled in middle (Fig. 12); sternite VIII transverse and with broadly convex posterior margin; spermatheca as in Fig. 14, similar to that of other species of the subgenus Masuria. 

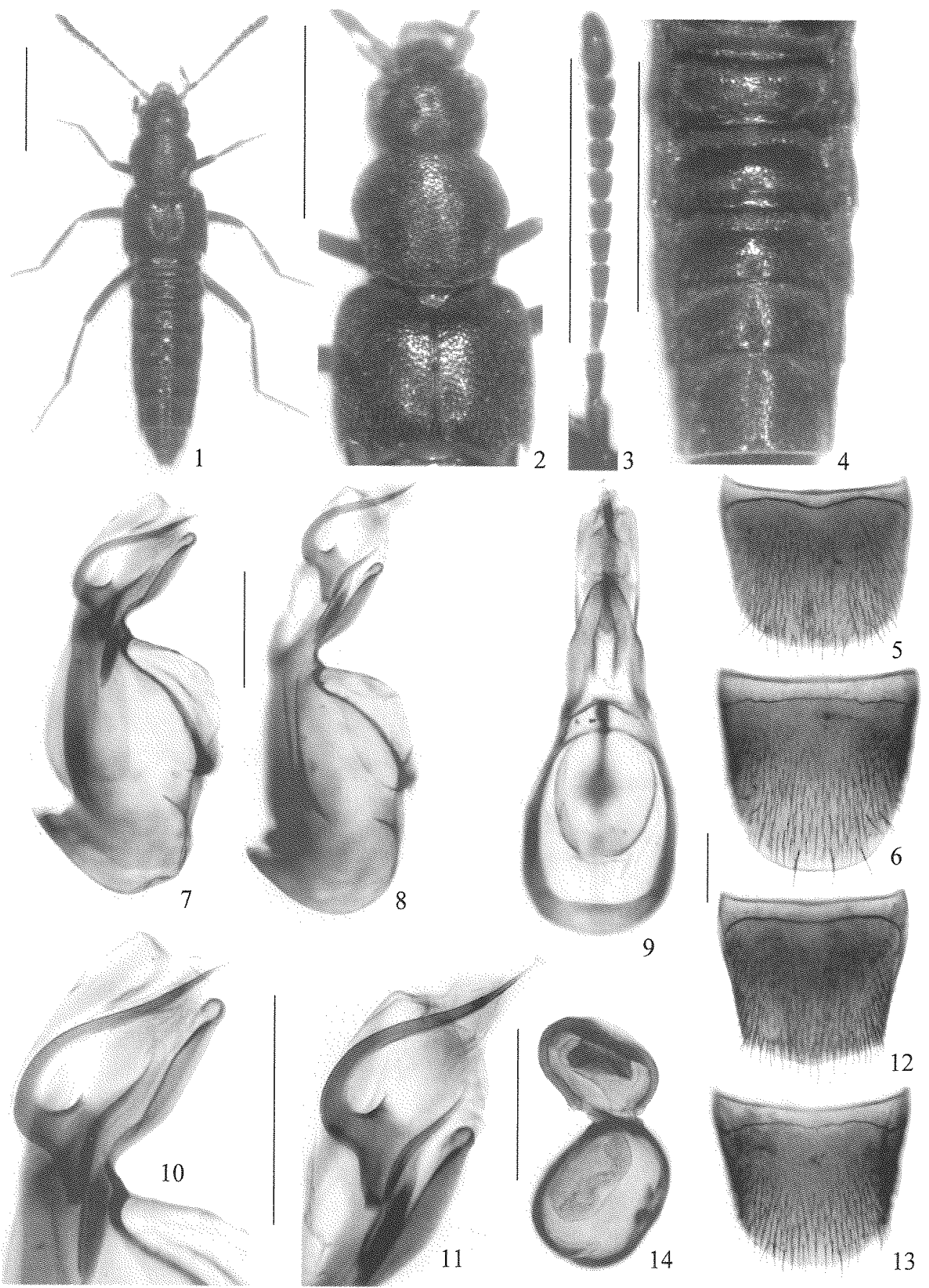

Figs. 1-14: Mastria kleebergi sp. n.: habitus (1); forebody (2); antenna (3); abdominal segments III-VII (4); $\sigma$ tergite VIII (5); $0^{*}$ sternite VIII (6); median lobe of aedeagus in lateral and in ventral view (7-9); apical part of median lobe of aedeagus in lateral view (10-11); ㅇt tergite VIII (12); 우 sternite VIII (13); spermatheca (14). Scale bars: $1-4: 1.0 \mathrm{~mm} ; 5-13: 0.2 \mathrm{~mm} ; 14: 0.1 \mathrm{~mm}$. 
Etymology: The species is dedicated to Andreas Kleeberg, who collected most of the material treated in the present paper, including the majority of the type specimens of this species.

\section{Comparative notes:}

Masuria kleebergi is most similar to M. spectata, from which it is distinguished especially by the different morphology of the aedeagus. In $M$. spectata, the median lobe is notched at the base of the ventral process. For distinction from the sympatric $M$. follita and other species of the genus see the comparative notes below and the key, respectively.

\section{Distribution and bionomics:}

The known distribution is confined to several localities in the surroundings of Nyimare, Rolwaling Himal, eastern Nepal, where the types were found at altitudes of 2600$3300 \mathrm{~m}$. At least two of the specimens were collected from wet moss in the vicinity of a waterfall. One dissected female had three mature eggs in the ovaries.

Masuria (Masuria) follita sp. n. (Figs. 15-26)

Type material:

Holotype o: Ost-Nepal, Rolwaling Himal / Rolwaling Tal, Nyimare, 3300 m, 19.05. 2000, leg. A. Kleeberg / Holotypus ơ Masuria follita sp. n. det. V. Assing 2006 (cAss). Paratypes: 4 exs.: same data as holotype (cKle, cAss); 5 exs.: Ost-Nepal, Rolwaling Himal / Rolwaling Tal, Umg. Nyimare, 3300 m, Spritzmoos, 18.05.2000, leg. A. Kleeberg (cKle, cAss); 6 exs.: Ost-Nepal, Rolwaling Himal / Rolwaling Tal, zw. Simigaon u. Nyimare, $2700 \mathrm{~m}, 17.05 .2000$, leg. A. Kleeberg (cKle).

\section{Description:}

Species of relatively small size, 3.0-3.6 mm. Habitus as in Fig. 15. Body blackish; legs brown, with the tarsi sometimes slightly paler; antennae dark brown, with the basal 3-4 antennomeres reddish brown.

Head with very dense, moderately coarse, and well-defined puncturation, interstices mostly reduced to narrow ridges and without microsculpture; eyes bulging, distinctly projecting from lateral outline of head (Fig. 16). Antennae relatively short (Fig. 17); preapical antennomeres approximately 1.5 times as wide as long.

Pronotum relatively slender, approximately 1.25 times as wide as head and approximately 1.15 times as wide as long; lateral margins widest a short distance anterior to middle, convexly dilated, but not angled, usually shallowly concave between lateral and posterior angles; posterior angles well-marked; near posterior angles usually with shallow, sometimes indistinct impression; puncturation similar to that of head; interstices without or with very shallow microsculpture (Fig. 16).

Elytra approximately 1.35 times as wide and about 0.95 times as long as pronotum; puncturation similar to that of pronotum, but slightly sparser and sometimes slightly coarser; interstices narrower than diameter of punctures (Fig. 16). Hind wings fully developed. Legs not particularly long and slender; metatarsomere I almost as long as the combined length of II and III. 

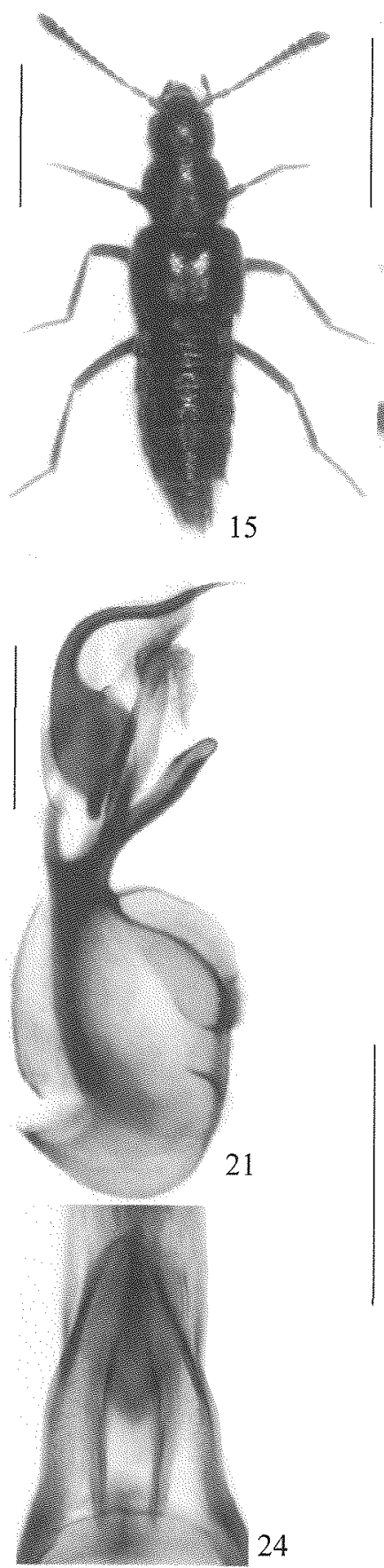

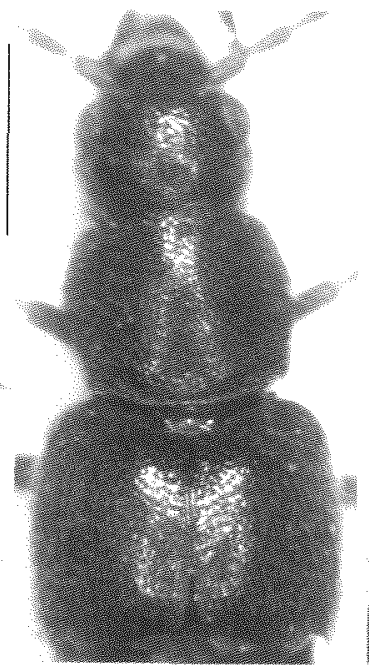

16

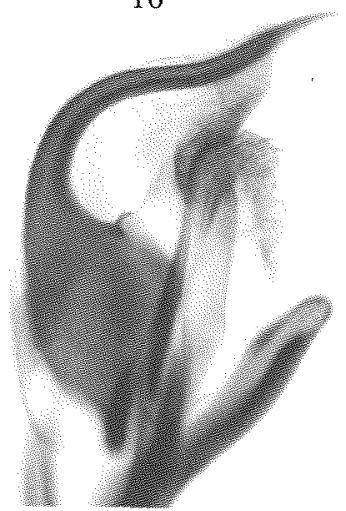

22

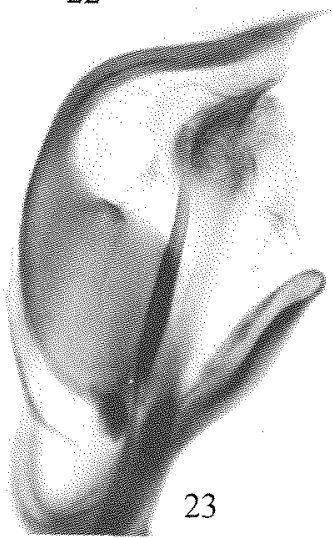

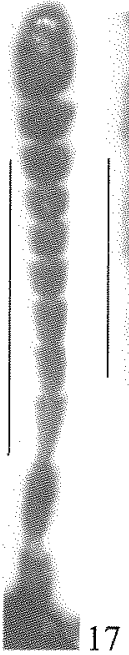

17
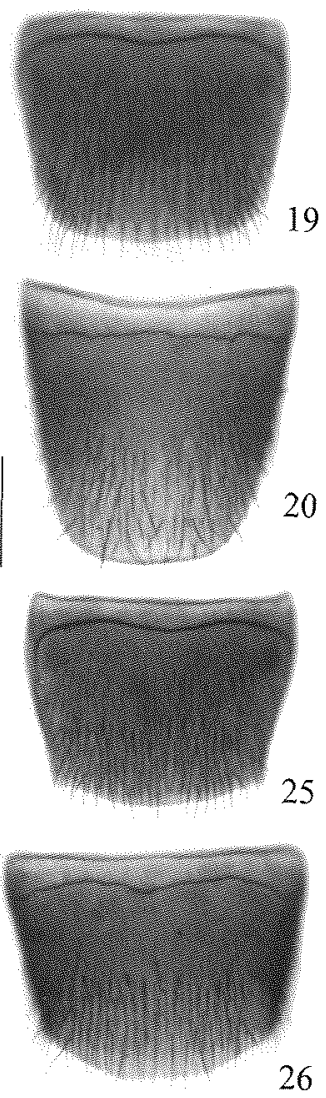

Figs. 15-26: Masuria follita sp. n.: habitus (15); forebody (16); antenna (17); abdominal segments III-VII (18); $\sigma^{*}$ tergite VIII (19); $\sigma^{*}$ sternite VIII (20); median lobe of aedeagus in lateral view (21); apical part of median lobe of aedeagus in lateral and in ventral view (22-24); $q$ tergite VIII (25); $q$ sternite VIII (26). Scale bars: 15: $1.0 \mathrm{~mm}$; 16-18: 0.5 mm; 19-26: $0.2 \mathrm{~mm}$. 
Abdomen approximately $0.80-0.85$ times as wide as elytra, anteriorly (segments III-V) subparallel, posteriorly (segments VI and following) weakly tapering; puncturation very dense and somewhat granulose in anterior impressions of tergites III-V, fine and very dense in posterior halves of tergites III-V and on all of tergite VI, slightly less dense on tergite VII; pubescence greyish and decumbent; surface without distinct microsculpture and with subdued shine owing to the dense puncturation and pubescence; posterior margin of tergite VII with pronounced palisade fringe (Fig. 18).

$\checkmark$ : tergite VIII transverse and with weakly convex posterior margin (Fig. 19); sternite VIII oblong, its posterior margin broadly convex (Fig. 20); median lobe of aedeagus with large-based flagellum-like structure in internal sac (Figs. 21-24).

q : tergite VIII transverse and with convex posterior margin (Fig. 25); sternite VIII transverse, its posterior margin truncate in middle (Fig. 26); spermatheca similar to that of M. kleebergi (cf. Fig. 14).

Etymology: The name (Lat., adj.: with a sack or bellow) refers to the conspicuous shape of the base of the flagelloid structure in the internal sac of the aedeagus.

\section{Comparative notes:}

From the similar sympatric and syntopic $M$. kleebergi, $M$. follita is at once distinguished by the shorter antennae with distinctly transverse preapical antennomeres, by the distinctly shorter legs and tarsi, the posteriorly less distinctly tapering abdomen, the denser abdominal puncturation, as well as by the distinctly smaller aedeagus with a less pronounced crista apicalis and an internal flagelloid structure of completely different shape. From the sympatric $M$. loebli and $M$. sculpticollis, it is easily separated by the different morphology of the aedeagus, as well as by the distinctly darker coloration (M. loebli) and the much more slender pronotum with less pronounced lateral angles and with well-defined puncturation (M. sculpticollis). For distinction from other species of the genus see the key below.

Distribution and bionomics:

The known distribution is confined to several localities in the surroundings of Nyimare, Rolwaling Himal, eastern Nepal, where the types were collected at altitudes of 2700$3300 \mathrm{~m}$. Some of the specimens were collected from wet moss in the vicinity of a waterfall.

Masuria (Masuria) sculpticollis sp. n. (Figs. 27-32)

Type material:

Holotype \%: Ost-Nepal, Rolwaling Himal / Rolwaling Tal, Nyimare, 3300 m, 19.05. 2000, leg. A. Kleeberg / Holotypus o Masuria sculpticollis sp. n. det. V. Assing 2006 (cAss). Paratype $q:$ same data as holotype (cKle).

\section{Description:}

Species of intermediate size, $4.0-4.3 \mathrm{~mm}$. Habitus as in Fig. 27. Body blackish, with the tarsi yellowish to yellowish brown; antennae with the basal 3-4 antennomeres reddish brown and the apical antennomeres blackish brown. 


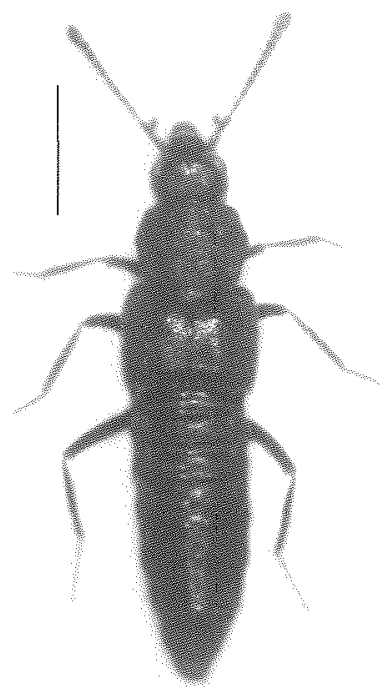

27
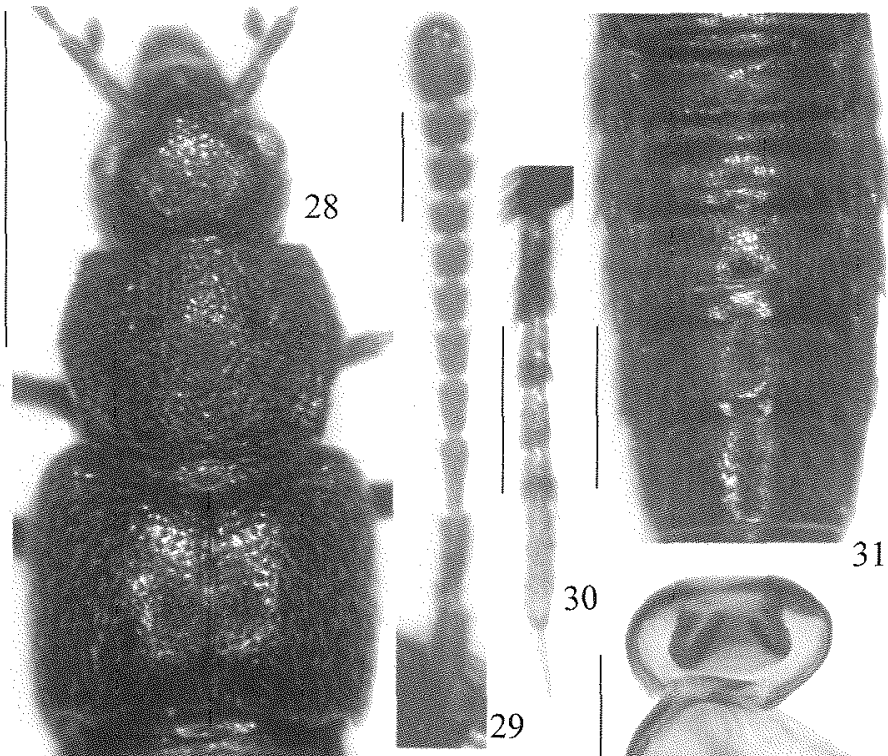

30

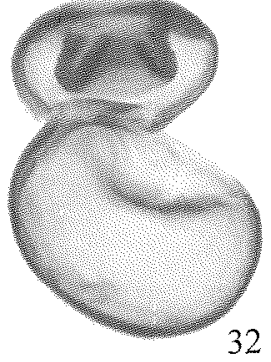

36

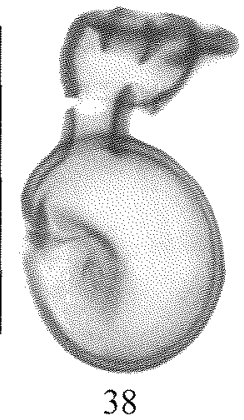

37

Figs. 27-38: Masuria sculpticollis sp. n. (27-32) and M. brevipennis sp. n. (33-38): habitus (27, 33); forebody (28, 34); antenna (29); metatarsus (30); abdominal segments III-VII (31); spermatheca $(32,38)$; head in lateral view (35); apical part of antenna (36); 9 sternite VIII (37). Scale bars: 27-28, 33:1.0 mm; 31, 34-35: $0.5 \mathrm{~mm} ; 29-30,36-37: 0.2 \mathrm{~mm} ; 32,38: 0.1 \mathrm{~mm}$.

Head with dense, rather coarse, and well-defined puncturation, interstices much narrower than average diameter of punctures and without microsculpture; eyes bulging, distinctly projecting from lateral outline of head (Fig. 28). Antennae moderately slender (Fig. 29); preapical antennomeres approximately 1.5 times as wide as long. 
Pronotum 1.40-1.45 times as wide as head and 1.25-1.30 times as wide as long; lateral margins distinctly angled a short distance anterior to middle, more or less straight (i. e. not sinuate) between lateral and posterior angles; posterior angles well-marked; puncturation highly distinctive: very coarse, rugose, and confluent (i. e. ill-defined) everywhere; surface almost matt (Fig. 28).

Elytra approximately 1.2 times as wide and 0.9 times as long as pronotum; puncturation coarse (more so than that of head), rather dense (but less so than that of head), and welldefined; interstices on average narrower than diameter of punctures. Hind wings apparently fully developed. Metatarsus not distinctly elongated; metatarsomere I shorter than combined length of II and III (Fig. 30).

Abdomen approximately 0.85 times as wide as elytra, widest at base (segments III/IV), gradually tapering towards apex; puncturation fine, very dense on tergite III, distinctly sparser on posterior than on anterior tergites; pubescence greyish and decumbent; surface without distinct microsculpture; posterior margin of tergite VII with pronounced palisade fringe (Fig. 31).

o: unknown.

i: posterior margin of tergite VIII broadly convex and with very long thin marginal setae; posterior margin of sternite VIII broadly convex; spermatheca not distinctive (Fig. 32), similar to that of other Masuria species.

Etymology: The name (Lat., adj.) refers to the strongly sculptured pronotum.

\section{Comparative notes:}

The species is readily distinguished from all other species of the genus by the coarsely and rugosely punctured pronotum.

\section{Distribution and bionomics:}

The types were collected in only one locality in the Rolwaling Himal at an altitude of $3300 \mathrm{~m}$. Additional bionomic data are not available.

\section{Masuria (Oncosomechusa) yunnanica AssING}

Additional material examined: $1 \%$, China, N-Yunnan, Diqing Tibet Aut. Pref., Zhongdian Co., Bitai Hai Lake area, $29 \mathrm{~km}$ ESE Zhongdian, $27^{\circ} 44 \mathrm{~N}, 99^{\circ} 59 \mathrm{E}, 3540 \mathrm{~m}$, creek valley, degraded mixed forest, litter, moss, dead wood, 1.VI.2005, leg. Schülke (cSch).

The specimen was collected near the type locality of this species, whose description is based on a single male holotype.

Masuria (Oncosomechusa) brevipennis sp.n. (Figs. 33-38)

Type material:

Holotype ㅇ: China (N-Yunnan) Zhongdian Co., $55 \mathrm{~km} \mathrm{~N}$ Zhongdian, $28^{\circ} 19.8 \mathrm{~N}$, $99^{\circ} 45.7 \mathrm{E}, 3800 \mathrm{~m}$ (primary mixed forest, Rhodod., dead wood, leaf litter, mushrooms, moss), 18.VIII.2003, Wrase [07] / Holotypus o Masuria brevipennis sp. n. det. V. Assing 2006 (cAss). 


\section{Description:}

$2.7 \mathrm{~mm}$. Habitus as in Fig. 33. Body castaneous to dark brown, with the abdominal apex (segment VIII), the legs and the base of the antennae distinctly paler, yellowish brown to rufous.

Head wedge-shaped, with moderately dense, shallow, but well-defined puncturation; interstices narrower than average diameter of punctures and without microsculpture; eyes small (Fig. 35), shorter than postocular region in dorsal view and not projecting from lateral outline of head (Fig. 34). Antennae short; antennomere III about 1.5 times as long as wide, IV approximately as long as wide, $\mathrm{V}$ weakly transverse, $\mathrm{V}$-X increasingly transverse and of increasing width, VIII-X approximately twice as wide as long (Fig. 36).

Pronotum 1.25 times as wide as head and 1.30 times as wide as long; maximal width approximately in the middle; lateral margins simply convex in dorsal view; posterior angles weakly marked; puncturation similar to that of head, but slightly denser and finer; interstices without microsculpture and shining (Fig. 34).

Elytra approximately 1.2 times as wide and 0.5 times as long as pronotum; puncturation similar to that of pronotum; interstices without microsculpture and shiny (Fig. 34). Hind wings completely reduced. Legs of moderate length, metatarsomere I approximately as long as the combined length of II and III.

Abdomen approximately as wide as elytra, widest at segment $V$; puncturation fine, very dense on tergites III-VI and slightly less dense on tergite VII; interstices with distinct microsculpture; posterior margin of tergite VII without palisade fringe; posterior margin of tergite VIII distinctly convex.

$0^{*}$ : unknown.

\%: sternite VIII transverse, middle of posterior margin weakly concave in middle (Fig. 37); spermatheca as in Fig. 38.

Etymology: The name (Lat., adj.) refers to the remarkably short elytra.

\section{Comparative notes:}

The species is readily distinguished from all other Chinese representatives of the genus by its extremely short elytra alone. From $M$. chinensis and $M$. yunnanica, the only other species of the subgenus Oncomechusa known to occur in China, it is additionally separated by the shorter antennae, the shorter legs with shorter tarsi, the more slender pronotum (in relation to head), as well as by smaller body size.

\section{Distribution and bionomics:}

The known distribution is confined to the type locality some $50 \mathrm{~km}$ to the north of Zhongdian, northern Yunnan, where the holotype was discovered in a mixed primary forest at an altitude of $3800 \mathrm{~m}$.

\section{Key to the species of Masuria}

In the following key, references to illustrations in the literature are abbreviated as follows: A98 = Assing (1998); A04 = Assing (2004); P89 = PACE (1989); P98 = PACE (1998). The distinguishing characters of $M$. ferruginea, M. rubida, $M$. rufescens, $M$. besucheti, and 
M. tashigaonensis, of which no material was seen, are based on the descriptions and key provided by PACE (1989).

1. Elytra very short, at most 0.7 times as long as pronotum; hind wings reduced. Lateral margins of pronotum distinctly dilated, abruptly convex to distinctly angled in anterior half. Posterior angles of pronotum well-marked. Abdomen at least as wide as elytra or nearly so; posterior margin of tergite VII without palisade fringe. Subgenus Oncosomechusa. ....... 2 Elytra longer, distinctly more than 0.7 times as long, usually approximately as long as pronotum; hind wings present. Lateral margins of pronotum more or less evenly convex in dorsal view, sometimes with maximal width in anterior half. Abdomen distinctly narrower than elytra; posterior margin of tergite VII with palisade fringe. Subgenus Masuria. .... 7

2. Species from the Himalaya (Nepal and northern India). ............................................... 3

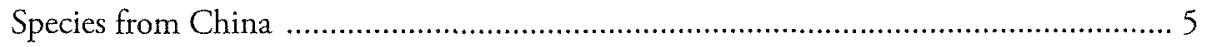

3. Coloration of body yellowish red to reddish. Aedeagus and spermatheca as in Figs. P89: 44-47. Central Nepal. M. martensi (PACE)

Coloration of body darker brown. 4

4. Eyes larger, more than half the length of postocular region in dorsal view. Pronotum less transverse (Fig. P89: 39). Spermatheca as in Fig. P89: 40 (male unknown). Northern India: Darjeeling district. M. besucheti $(\mathrm{PACE})$

Eyes very small, less than half the length of postocular region in dorsal view. Pronotum more transverse (Fig. P89: 42). Spermatheca as in Fig. P89: 41 (male unknown). Nepal: Khandbari district. M. tashigaonensis PACE

5. Elytra approximately 0.7 times as long as pronotum. Pronotum distinctly dilated in anterior half (Fig. A04: 19). Puncturation of forebody distinct and well-defined. Eyes longer than postocular region in dorsal view (Fig. A04: 19). Antennomere IV distinctly (approximately $1.5 \mathrm{x}$ ) oblong. Legs, especially metatarsus, long and slender. Abdomen without microsculpture. Aedeagus as in Fig. A04: 20. China: N-Yunnan. M. yunnanica AssING

- Elytra shorter, less than 0.6 times as long as pronotum. Pronotum with evenly convex lateral margins in dorsal view. Puncturation of forebody shallow. Eyes distinctly shorter than postocular region in dorsal view. Antennomere IV approximately as long as wide. Legs shorter. Abdomen with microsculpture. 6

6. Elytra approximately 0.55 times as long as pronotum. Antennae distinctly longer and more slender; antennomeres V-VII not or only indistinctly transverse. $\sigma^{t}$ : tergite VII with broadly and distinctly concave (!) posterior margin. Aedeagus as in Figs. P98: 2-3. Spermatheca as in Fig. P98: 4. Gansu: Xinlong Shan. M. chinensis PACE Elytra approximately 0.50 times as long as prontoum (Fig. 34). Antennae shorter; antennomeres V-X distinctly transverse (Fig. 36). Spermatheca as in Fig. 38 ( $\sigma^{*}$ unknown). NYunnan: surroundings of Zhongdian. M. brevipennis sp. $\mathrm{n}$.

7. Species from northern India with rufous to light brown pronotum and elytra. ............. 8 Species unknown from northern India and/or with blackish pronotum. .................... 10

8. Larger species. Elytra approximately as long as pronotum or nearly so. ......................... 9 Smaller species. Elytra somewhat shorter than pronotum (Fig. P89: 30). Aedeagus as in Figs. P89: 31-32. Chakrata district, Mussoori. M. ferruginea CAMERON 
9. Eyes smaller, shorter than postocular region in dorsal view. Pronotum less transverse; lateral margins with long setae (Fig. P89: 27). Aedeagus as in Figs. P89: 28-29. Ghum district.

M. rubida CAMERON

Eyes larger, as long as postocular region in dorsal view. Pronotum more transverse; lateral margins without long setae (Fig. P89: 24). Aedeagus as in Figs. P89: 25-26. Ghum district.

M. rufescens CAMERON

10. Pronotum relatively large, at least 1.4 times as large as head, and with conspicuously coarse, rugose, and confluent puncturation; surface almost completely matt. Coloration of body predominantly black. Eastern Nepal: Rolwaling Himal.

M. sculpticollis sp. n.

- Pronotum in most species distinctly less than 1.4 times as large as head; puncturation not conspicuously rugose, finer, and in most species well-defined and with glossy interstices. Species with a conspicuously coarsely and densely punctate pronotum are of brown to dark brown coloration.

11. Species from China. Flagelloid structure in internal sac of aedeagus long and with small base (Fig. A04: 14-15). Yunnan: Dali. M. daliensis Assing

Species from the Himalaya. Flagelloid structure in internal sac of aedeagus usually shorter and with larger and often more or less anchor-shaped base. (For a reliable identification of the following species, an examination of the aedeagus is usually essential.) 12

12. Pronotum with coarse and very dense puncturation; interstices very narrow, microsculptured, and either with reduced or almost completely without shine. 13

Pronotum with more or less dense, but not coarse puncturation; interstices usually without microsculpture and with some shine.

13. Eyes longer than postocular region in dorsal view. Aedeagus relatively small and with relatively weakly pronounced crista apicalis (Figs. P89: 10-12, A98: 4h). Widespread species: Nepal, northern India.

M. plumbea CAMERON

Eyes shorter than postocular region in dorsal view. .14

14. Aedeagus much larger and with relatively short ventral process; base of flagelloid structure small (Figs. A98: 4a-b). Nepal: Khandbari district. M. rugosepunctata Assing Aedeagus small and with long ventral process; base of flagelloid structure larger (Figs. P89: 18-19). Northern India: Ghum district. M. parva Cameron

15. Pronotum with shallow, dense, and partly ill-defined puncturation. 16

Pronotum with distinct, more or less dense, and well-defined puncturation.

16. Preapical antennomeres (IX-X) distinctly transverse, approximately 1.5 times as wide as long (Fig. 17). Flagelloid structure in internal sac of aedeagus with very large base (Figs. 21-23). Nepal: Rolwaling Himal. M. follita sp. $\mathrm{n}$.

Preapical antennomeres (IX-X) weakly transverse, less than 1.5 times as wide as long. Flagelloid structure in internal sac of aedeagus with smaller base. 17

17. Median lobe of aedeagus smaller and in lateral view with straight ventral process; ventral process without pronounced lateral folds (Figs. A04: 6-7). Nepal: Annapurna, Dhaulagiri. M. annapurnae Assing

Median lobe of aedeagus distinctly larger and in lateral view with slightly bent ventral process; ventral process with lateral folds. 
18. Median lobe of aedeagus in lateral view dented between base of ventral process and crista apicalis (Figs. P89: 22-23). Nepal: Bagmati province.

M. spectata PACE

Median lobe of aedeagus in lateral view not dented between base of ventral process and crista apicalis (Figs. 7-11). Nepal: Rolwaling Himal.

M. kleebergisp. n.

19. Pronotum with moderately dense puncturation; width of interstices on average at least half the diameter of punctures and distinctly glossy. Aedeagus as in Figs. P89: 2-3. Central and eastern Nepal.

M. loebli PACE

- Pronotum with very dense puncturation; interstices narrower than half the diameter of punctures and with subdued shine. 20

20. Lateral margins of pronotum each with approximately 5 long setae, which are approximately as long as antennomere III. Aedeagus very large (Figs. P89: 14-15). Nepal: Khandbari district. M. kali $\mathrm{PACE}$

- Lateral margins of pronotum each with fewer (if any) and shorter setae. Aedeagus smaller. 21

21. Whole body, including abdomen, very densely punctate, almost matt. Abdomen (including tergite VII) with relatively coarse and dense puncturation, interstices distinctly narrower than punctures. Pronotum relatively large, approximately 1.2 times as wide as long (Fig. P89: 34). Lateral margins of pronotum in posterior half not sinuate in dorsal view. Aedeagus as in Figs. P89: 35-36. Central and eastern Nepal. M. smetanai $\mathrm{PACE}$

- Body less densely punctate and with shiny interstices. Abdominal tergite VII with much finer and sparser puncturation, interstices distinctly wider than diameter of punctures. ..

22. Antennae shorter, antennomere $\mathrm{X}$ more than 1.5 times as wide as long. Legs shorter; metatarsomere I barely as long as the combined length of II and III; III approximately twice as long as wide. Coloration darker, femora blackish. Aedeagus as in Figs. P89: 6-7, A98: 3h. Widespread species: Nepal, northern India. M. picipes CAMERON

- Antennae longer, antennomere X less than 1.5 times as wide as long. Legs longer; metatarsomere I at least as long as - usually longer than - the combined length of II and III; III clearly more than twice as long as wide. Coloration paler, femora brown. 23

23. Pronotum more transverse, approximately 1.25 times as wide as long. Metatarsus shorter and with less elongated metatarsomere I. Aedeagus with shorter ventral process; flagelloid structure in internal sac with more slender and anchor-shaped base (Figs. A98: 5a-b). Nepal: Rasuwa district. $M$. ancoriformis AssING

- Pronotum less transverse, approximately 1.15 times as wide as long. Metatarsus long and with elongated metatarsomere I. Aedeagus with longer ventral process; flagelloid structure in internal sac with more massive base (Figs. A98: 3a-b). Nepal: Khandbari district.

M. longicomis Assing

\section{Acknowledgements}

My thanks are extended to Andreas Kleeberg and Michael Schülke for the loan of material and for the generous gift of the holotypes described in this paper. 


\section{References}

Assing, V. 1998: New species and records of Masuria Cameron from Nepal (Coleoptera, Staphylinidae, Aleocharinae). - Revue suisse de Zoologie 105: 777-787.

Assing, V. 2004: New species and records of Masuria Cameron from Nepal and China (Coleoptera: Staphylinidae, Aleocharinae). - Linzer biologische Beiträge 36: 579-588.

PACE, R. 1989: Aleocharinae nepalesi del Museo di Ginevra. Parte II. Revisione del genere Masuria CAMEron (Coleoptera, Staphylinidae). - Revue suisse de Zoologie 96: 713-727.

PACE, R. 1998: Aleocharinae della Cina. Parte I. (Coleoptera, Staphylinidae). - Revue suisse de Zoologie 105: 139-220.

\section{Author's address:}

Dr. VOLKer Assing

Gabelsbergerstraße 2

D - 30163 Hannover

Germany

e-mail: vassing.hann@t-online.de 